\title{
Based on research on the demand for "Chinese + vocational skills" project by Confucius institutes in Asia and Africa, discussing on Chinese professional standards going global
}

\section{Zenghui Du}

Nanjing Vocational University of Industry Technology

About the author: Zeng Hui Du (1974-), female, associate professor, Master of International Chinese Language Education, Research direction: International Chinese language education, Cultural differences between China and the West

Funded Project: international Collaborative Research gjzj2019-01: research on ways to enhance Chinese cultural identity of overseas students in the context of "One Belt and One Road"

Abstract: The implementation of the "One Belt and One Road" initiative and Chinese education opening policy have created conditions for comprehensively promoting vocational education reform and high-quality development. Through the questionnaire survey of 70 countries in Asia and Africa on the demand for vocational skills and vocational skill level certificates, this paper analyzes the needs of Asia and Africa respectively, and then takes 8 countries as the pilot to analyze the specific needs of each country. Domestic vocational colleges can seek the corresponding state to cooperate according to what high level professional they owned which help China's vocational education model and education standards go global, and help Chinese-funded enterprises train local employees, and help China's technical and industrial standards go global.

Keywords: "One Belt and One Road"; Demand for vocational skills; Vocational skill level certificate; China standard

\section{Research background}

Sun Chunlan, vice Premier of the State Council and chairman of the Confucius Institute Headquarters proposed that Confucius Institutes should implement the "Chinese + Vocational Skills" program at the opening ceremony of the 2019 International Conference on Chinese Language Education. Given that the "Chinese + Vocational Skills" project is at its initial stage, it has a certain foundation for development in Asian and African countries, it still needs to be clarified at the macro and medium levels, such as the overall framework of the project and the ideas for its promotion. Therefore, it is necessary to carry out special research on the "Chinese + Vocational Skills" project of Confucius Institutes in Asian and African countries.

\section{Statistical overview and analysis}

The survey questionnaire was designed for Confucius institutes and classrooms in Asia and Africa. A total of 140 questionnaires were collected, and 136 were valid. The questionnaire is designed in five aspects: 1) Your country; 2) Your Confucius Institute; 3) What vocational skills have you learned are urgently needed in the local area? 4) Which vocational certificates might you be interested in according to the local conditions? 5) Which industries or vocational education fields do you think should be given priority to carry out pilot work?

The statistical data of the above five questions are as follows:

The 136 valid questionnaires collected this time cover a total of 70 countries, including 22 Asian countries and

Copyright (C) 2020 Zenghui Du

doi: 10.18282/le.v9i5.1194

This is an open-access article distributed under the terms of the Creative Commons Attribution Non-Commercial License

(http://creativecommons.org/licenses/by-nc/4.0/), which permits unrestricted non-commercial use, distribution, and reproduction in any medium, provided the original work is properly cited. 
48 African countries. Thailand, Japan, South Africa and Pakistan received the most questionnaires, and 28 countries received more than two questionnaires. The 136 valid questionnaires included 119 Confucius Institutes and 17 Confucius classrooms.

\subsection{Vocational skills that are urgently needed locally}

According to statistics, tourism, construction, tour guide, agricultural technology, auto repair, e-commerce, logistics and other vocational skills in the surveyed countries demand is large, but the demand has both similarities and differences.

At present, Thailand, Malaysia and Indonesia in Asia and South Africa, Egypt, Ethiopia, Kenya and Zambia in Africa are selected as the specific analysis objects.

Thailand was most in need of professional skills for translation, accounting for $21 \%$, followed by Agricultural Technology (13\%) and Chinese-Thai Lawyers (8\%). In addition, Logistics, E-Commerce and Airport Management accounted for more than 5\%. Malaysia is in urgent need of vocational skills in Construction, Cross-Border E-Commerce, Information Technology, High-Speed Rail Technology and Aquaculture. Indonesia is urgent need of Vocational Skills and Engineering.

The most urgent vocational skills in South Africa are Automobile Maintenance, Track Technology and Electromechanical Integration. Other skills, such as Computer, Logistics, Mechanical Technology and Tour Guide, are also in great demand. In addition, there are also demands for Professional Chinese and Early Education. Job skills in demand include Marketing, Tour Guides, Traditional Chinese Medicine, Information Technology, Electrical and Mechanical Engineering, Advertising Design And Planning, and Desert Management. The most urgently needed vocational skills in Ethiopia are Industrial Automation, Railways, Roads, Bridges, Construction, Mechanical Engineering and Mechatronics. Kenya's greatest need for vocational skills is Business Administration, Construction, Engineering, Tourism, Law and Finance. Zambia is in dire need of skills in Electricians, Welders, Machining, Business Administration, Engineering Management, Computer Networking and Medicine.

\subsection{Requirements for vocational certificates}

According to the statistics of the recovery questionnaire, in Asia and Africa, the top three certificates in demand are Automobile Application and Maintenance, E-Commerce Data Analysis, Logistics Management, Online Store Operation and Promotion, Building Information Model, Special Welding Technology, Intelligent Finance and Tax Professional Skills. But for a certain region or a certain country, there are differences in demand.

Taking Thailand, Malaysia and Indonesia in Asia and South Africa, Egypt, Ethiopia, Kenya and Zambia in Africa as examples, this difference is further analyzed and compared. There are as many as 13 vocational certificates that Thailand is most interested in, including E-Commerce Data Analysis, Logistics Management and Elderly Care, followed by Maternal and Child Care, Industrial Robot Application Programming, Automobile Applicationand Maintenance. The most interesting vocational certificates in Malaysia are building Information Modeling (BIM), E-Commerce Data Analysis, Online Store Operation Promotion, etc. In Indonesia, there are as many as 12 kinds of vocational certificates that are most interested in. However, due to the small sample size obtained from the survey, more needs and proportion in Indonesia still need to be further investigated and analyzed.

In South Africa, there are as many as nine vocational certificates of interest, namely, E-Commerce Data Analysis, Industrial Robot Operation and Maintenance, Industrial Robot Application Programming, and other urgent needs include Building Information Modeling (BIM), Elderly Care, Automobile Application and Maintenance. The most interesting vocational certificates in Egypt are Automobile Application and Maintenance, Logistics Management and E-Commerce Data Analysis, followed by Front-End Development, Special Welding Technology, Online Store Operation and Promotion, Intelligent New Energy Vehicles. Ethiopia are most interested in professional level certificate up to 11 species, respectively is Sensor Network Application Development, E-Commerce, Data Operation and Operational Analysis, Industrial Robots, Industrial Robot Application Programming, Building Information Model (BIM), Car Use And Maintenance, The Front-End Development, Special Welding Technology, Business Promotion, Logistics Management, Intelligent Taxation Vocational Skills, Intelligent New Energy Vehicles. The most interesting 
vocational certificates in Kenya include Building Information Modeling (BIM), Logistics Management, Vehicle Application And Maintenance, E-Commerce Data Analysis, Online Store Operation Promotion, And Intelligent Finance And Tax Vocational Skills. The most interesting vocational certificates in Zambia cover Building Information Modeling (BIM), Web, Sensor Network Application Development, Industrial Robot Operation And Maintenance, Industrial Robot Application Programming, Maternal and Child Care, Automobile Application and Maintenance, Special Welding Technology, Logistics Management, etc.

According to the collected questionnaires in Africa, Automobile Application and Maintenance, Logistics Management and E-Commerce Data Analysis are the vocational certificates that are of interest to all institutes in Africa.

\subsection{The prior pilot industries or fields to be recommended}

Through research, it is suggested that priority should be given to pilot industries or fields such as Tourism, Agriculture, Automobile, Tour Guide, E-Commerce, Engineering, etc., which are highly consistent with the local urgently needed vocational skills, further indicating that the project must be carried out in combination with the actual economic and social development of the country and adhere to the demand-oriented approach. In particular, Thailand suggests that priority be given to selecting pilot industries or areas such as Logistics, E-Commerce, Business Administration and Traditional Chinese Medicine. Malaysia proposes to give priority to Construction, Information Technology, High-Speed Rail Technology and Infrastructure Construction. Indonesia recommends giving preference to Artificial Intelligence. Through the above analysis, it can be seen that there are large regional differences in the proposed pilot areas of the three countries

South Africa suggests that priority be given to Automobile Manufacturing and Maintenance, Tourism, Professional Chinese, Huawei ICT, Mechatronic Integration, Electrical Automation, Early Education and other pilot industries or fields. Egypt suggested that Preference be given to Chinese, Traditional Chinese Medicine and Information Technology. Ethiopia recommends that priority be given to electronic and electrical automation technology, mechatronics (robotics applications). Kenya recommends prioritizing Logistics, Construction, Tourism, Online Store Operation Management and Promotion. Zambia recommended that priority be given to Mining, Electronics and Engineering, Automobiles, Business Management, Information Technology and Smelting. The five African countries have some similarities in their pilot industries or fields, such as Automobile and Electromechanical Integration, but they also have some differences. In particular, Egypt has special suggestions for TCM.

\section{3. the conclusion}

1.Asia and Africa have a great demand for the "Chinese + Vocational Skills" program, and it should be the main task of Confucius Institutes to link language learning more closely with students' future career direction. Domestic higher vocational colleges can also seize this good opportunity to seek cooperation with Confucius Institutes. 2.The urgently needed industries and priority pilot industries are consistent with the urgently needed vocational certificates to a certain extent, which provides a basis for field research for higher vocational colleges to conduct individual certificate tests overseas. 3. Demand larger industry focusing on Tourism, Construction, Tour, Agriculture, Automobile Maintenance, Logistics, quality professional colleges and universities high level professional may consider the corresponding next docking cooperation in Asian and African countries, by writing the professional Chinese teaching materials, the selection of form a complete set of professional technology and language teachers and engineering and technical personnel to the hole to develop vocational education and training, as well as in the form of intercollegiate exchanges and cooperation. 4. Develop certificates according to local conditions. The relationship between Chinese standards and international standards should be handled correctly. Based on the existing domestic vocational skill level certificates, the localization development of certificates should be carried out according to the actual situation of the enterprises and industries in the country, so as to improve the universality of certificates. At the same time, we should give full play to the regulating role of certificates in talent introduction, assessment management and salary design, make certificates become the "stepping stone" and "touchstone" for employees' entry and promotion, gradually improve the recognition degree and value of certificates, establish the authority of certificates, and truly go global with Chinese standards. 


\section{References}

1. Sun Chunlan: deepen international Chinese education, let the world know more about China[EB/OL].2019-12-10. http://hn.people.com.cn/n2/2019/1210/c337651-33620002.html

2. Pengyi Sun and Dapeng Wei, Internal Communication Briefing on "Chinese + Vocational Skills" Project, held during the 2019 International Conference on Chinese Language Education [R], 201912

3. Du Zeng Hui. Local demand questionnaire on vocational education and professional level certificate in [EB/OL]. 2019-12-18. https://www.wjx.cn/jq/52226084.aspx, 